\title{
THE VICISSITUDES OF THE HERMENEUTIC PARADIGM IN THE STUDY OF LAW: TRADITION, FORMS OF LIFE AND METAPHOR
}

\author{
Carel Smith*
}

\begin{abstract}
Legal hermeneutics carries the hallmark of a genuine scientific paradigm. It is the locus of professional commitment, that is, a generally accepted view about the nature of legal adjudication. But as any genuine paradigm, legal hermeneutics also eludes the production of its full interpretation or rationalisation. Although most lawyers and legal scholars feel compelled to employ some standard set of methods, this consensus does not imply an underlying body of rules and assumptions that fully accounts for legal praxis and legal research. The paradigm of legal hermeneutics, flourishing on the level of legal praxis, is itself a subject of different schools of thought. This article explores different theories of law, sparked off by philosophical and legal hermeneutics. It argues that some of the weaknesses of hermeneutics are remedied by speech act theory. It discusses the increasing scientific interest in the role of metaphor in human thought and emphasises the import of the study of legal metaphor, which is inseparable from culture and tradition, for the study of law.
\end{abstract}

Keywords: hermeneutics, relativism, speech act theory, metaphor, culture and tradition, legal methodology.

If $\ldots$ the observer $\ldots$ does not give up any account of the manner in which members of the group who accept the rules view their own regular behaviour, his description of their life cannot be in terms of rules at all, and so not in the terms of the rule-dependent notions of obligation or duty.

(H.L.A. Hart, The Concept of Law (1994) at 89)

1

It seems that the least controversial statement one can make on the topic of legal adjudication is that it is a rule-governed activity. This modest claim rests upon at least two characteristics of legal adjudication. First, the paradigm of legal adjudication is the application of rules, whether or not these rules can be found in statutes or have to be extracted from precedents. ${ }^{1}$ Secondly, legal adjudication itself, the set of processes of interpretation and application, is guided by rules. After all, a large portion of the training as a legal professional is devoted to the acquisition of interpretative techniques and modes of reasoning, such as linguistic and systematic interpretation, analogical reasoning and reasoning from precedent. It is the mastery of these techniques, rather than mere knowledge about the law, that offers the seal of genuine legal craftsmanship. ${ }^{2}$

If legal adjudication is a rule-governed activity, both on the level of the law itself as well as on the level of the profession, legal adjudication, then, seems to be directed towards a text-rules, regulations, rulings and principles. Through these methodological standards, the text is recognised, interpreted and applied. This, at least, might explain the vast literature on the topic of legal adjudication. Different movements or schools, such as legalism, Freirechtsbewegung and Legal Realism, and their current counterparts like originalism, Critical Legal Studies, pragmatism and constructivism, vie with one another, challenging the assumptions and purposes of their rivals. Each school asserts to offer a more convincing account of the nature of legal adjudication and emphasises the practical import of the school to which the judge or official belongs. The stakes of

\footnotetext{
Senior Lecturer Legal Theory, Leiden University.

N. MacCormick, Legal Reasoning and Legal Theory (1978) at 45.

M. Koskenniemi, From Apology to Utopia. The Structure of International Legal Argument (2005) esp. the Epilogue.
} 
the debates are high, for the conversion from one school to another is supposed to affect the outcome of the processes of legal reasoning significantly - though one wonders how often a learned judge switches the presuppositions and tacit knowledge of her profession under the pressure of critical theory.

Among these schools, legal hermeneutics takes up a different position. It is not one school among the others, but it sits aside or, more precisely, on top of the row of competing schools that propagate one methodology as the proper one. The concern of legal hermeneutics is not how the judge ought to understand the law, but the act of understanding itself. It does not offer a particular methodology, neither does it prescribe which interpretive standards have priority in law, nor does it hold a hierarchy of legal values. Instead, it examines the conditions of understanding in general and of understanding the law in particular. The result is a phenomenology of understanding that includes legal schools of different colours, albeit not all colours. ${ }^{3}$ To the extent that legal hermeneutics offers an epistemology of the study of law that is accepted by most legal scholars, it might properly be said that hermeneutics serves as the paradigm for current European legal theory. ${ }^{4}$

Although hermeneutics offers a philosophical account of the nature of understanding, rather than a particular methodology how to conduct legal research, it nevertheless structures the way legal research is actually conducted, from the selection of relevant legal issues to the evaluation and criticism of the legal theories, doctrines and legal solutions. In this respect, one might say, philosophy and theory matter for praxis. ${ }^{5}$ In this article, I would like to address the implications of the hermeneutic paradigm for the nature of legal research. As legal hermeneutics functions as a paradigm, that is, as a generally accepted view about the nature of legal science, from which spring particular coherent traditions of legal theory and research, ${ }^{6}$ I will focus on one topic that ties those traditions together: the alleged distinction between object and subject. This topic, intimately connected with the predicament of relativism, explains the emergence of different traditions or schools that share the hermeneutic paradigm. In this article, I will argue that speech act theory, inspired by the works of the later Wittgenstein, offers an elegant solution for the problem of relativism that hermeneutics raises, but has not convincingly settled. I will argue, furthermore, that both hermeneutics and speech act theory point towards the import of culture in the study of law.

Before justifying the bold claim that the hermeneutic paradigm rules contemporary legal theory, I would like to dispel a potential misconception that stems from confusing the genesis of a conception with the theory that serves as its exemplary model. The thesis that most legal scholars endorse the hermeneutic paradigm merely expresses the

\footnotetext{
Movements like original intent, strict constructionism and textualism, for example, reject the claim of hermeneutics that meaning is not something 'given', but the result of the interplay between text and reader. Instead, these movements hold that the meaning is already 'there', that is, in the (legal) text or mind of the drafters. For a defence of textualism, see A. Scalia, A Matter of Interpretation. Federal Courts and the Law (1997); for a defence of original intent, see Keith E. Whittington, Constitutional Interpretation. Meaning, Original Intent, and Judicial Review (1999).

4 See J. Lenoble, 'Narrative Coherence and the Limits of the Hermeneutical Paradigm' in P. Nerhot (ed.), Law, Interpretation and Reality. Essays in Epistemology, Hermeneutics and Jurisprudence (1990) 127-168; B. Bix, 'H.L.A. Hart and the Hermeneutic Turn' (1999) 52 S.M.U. Law Review 167 at 181.

For the importance of theory, see M. Bal and I.E. Boer (eds.), The Point of Theory. Practices of Cultural Analysis (1994).

6 Cf. some of the descriptions of the concept of 'paradigm' by Kuhn: Thomas S. Kuhn, The Structure of Scientific Revolutions (1962, rev. ed. 1970 (with postscript), 1996) esp. ch. II. Although this concept plays a key role in Kuhn's work, he did not give a clear-cut definition of it. He calls it, among other things, an accepted example of actual scientific practice, a model from which spring particular coherent traditions of scientific research (p. 10), a single generally accepted view about the nature of something, a standard set of methods that every researcher felt forced to employ (p. 12), an accepted model or pattern (p. 20) and a disciplinary matrix (in the postscript to the 1970 edition, p. 182). Accordingly, I will use the concept of paradigm to connote both a shared viewpoint as well as a methodology, a conception, and a movement, etc.
} 
simple fact that current legal theory conceives of the processes of understanding the law in such way, that it could very well be described as hermeneutic. But the intellectual itinerary towards this position may never have crossed the path of philosophical (or legal) hermeneutics. The introduction of the participant's perspective into descriptive legal theory by H.L.A. Hart, for example, has been seen as a kind of 'hermeneutic turn' in legal philosophy, although Hart's legal philosophy is firmly embedded in analytical philosophy, rather than in phenomenology, of which philosophical hermeneutics derives its inspiration and borrows its vocabulary. ${ }^{7}$ And some authors, like the Dutch legal theorist Paul Scholten, have developed a legal methodology that has been rightly characterised as hermeneutical, albeit at a time that philosophical hermeneutics was still in the making. ${ }^{8}$ It is only with hindsight that we recognise the predecessor.

In this article, legal hermeneutics is used to denote a specific conception of the act of understanding phenomena such as law, a conception that is shared by most legal scholars, although only some of them have arrived at this view through philosophical hermeneutics.

What, then, is legal hermeneutics? And what makes it a paradigm for legal theory? To start with the first question: legal hermeneutics is a branch of philosophical hermeneutics. In order to understand legal hermeneutics, we have to turn to its source. For a full grasp of the ideas and thought of philosophical hermeneutics, we have to know what it is opposed to. Originally, hermeneutics was a discipline of the interpretation of sacred, legal or literary texts in the mid- $17^{\text {th }}$ century. ${ }^{9}$ Philosophical hermeneutics refers to the reflection upon understanding as such. The more general character of this project stems from a resistance against the hegemony of the natural sciences, whose compelling rise in the $18^{\text {th }}$ and $19^{\text {th }}$ century led to the predominance in all branches of knowledge of what was considered to be the scientific method par excellence: the study of phenomena from an external point of view in order to discover the laws that explain the movements and changes of nature and the vicissitudes of man and society. But according to Friedrich Schleiermacher (1768-1834) and Wilhelm Dilthey (1833-1911), the founding fathers of philosophical hermeneutics, phenomena such as religion, law and literature have to be studied differently. These phenomena are of a different kind - not natural phenomena, but manifestations of the human spirit. The purpose of the study of these phenomena is not explanation, but understanding. To understand a work of art, for instance, one is not confined to a causal explanation of its genesis by disclosing the material conditions that constitute it, nor to detached observation of the response or behaviour that it excites. This approach would then miss an entire dimension: the aspect of its value or meaning. Understanding a work of art means that we take into consideration the imprint it leaves on the affects of people. It requires that we ask how the work affects the inner life of those involved. But in so doing, we are no longer a detached observer whose observations are confined to regularities and causal relations. Understanding a work of art requires that we have to conceive of it in terms of the experiences of the inner life - hope, anger, remorse - a task that can only be properly performed if we bring along our own experiences of hope, anger and remorse. Only when we have experienced those affects ourselves are we able to understand the affects operative in others in their reception of works of art and other expressions of the human spirit.

According to Schleiermacher and Dilthey, the methodology of the humanities therefore differs fundamentally from those of the natural sciences. As the purpose of the humanities is 'understanding', its methodology is based not upon a categorical partition between object and subject, between the thing studied and the detached scientist, but

See Bix, above n. 4, at 167-168. Hart uses the term 'hermeneutics' in later descriptions of his earlier work: H.L.A. Hart, Essays in Jurisprudence and Philosophy (1983) at 14, 15.

8 J.J.H. Bruggink, Wat zegt Scholten over recht. Een rechtsfilosofische studie rond het "Algemeen Deel" (1983).

J. Starobinsky, 'Foreword' in F. Schleiermacher, Herméneutique, French transl. by M. Simon (1987) at 6. 
upon the involvement of the scholar, who is not a neutral observer, but whose experience of life is inextricably linked up with the act of understanding. Understanding, then, requires an internal point of view, the point of view of the participant.

This, in barest outline, is the main thesis of philosophical hermeneutics, and this thesis has spawned a whole literature on the distinctive features and problems of the methodology of the humanities. Philosophical hermeneutics bears the stamp of all genuine philosophy: its debates are thorough and profound as well as scholarly and esoteric. In this article, I will address only some of its main issues, as far as it has fuelled the debates on legal methodology. But before doing so, I still have to vindicate the claim that the hermeneutic paradigm is predominant in current legal theory.

\section{4}

To state that hermeneutics provide the model for legal theory is, in fact, making two claims. For legal theory is practiced on two levels. It is, on the one hand, the study of a particular legal regime so as to determine as precisely as possible what is prescribed or prohibited by the law on a certain topic. Legal theory here denotes the academic variety of legal adjudication or what is called legal doctrine. But legal theory, on the other hand, also denotes the study of law on a more abstract level. On this level, its concern is not the content of the law of a specific country or field, but the study of the features and function of law as a social institution, as distinguished from other institutions such as religion or morals. This is the province of legal sociology, anthropology and philosophy. My claim, then, is that on both levels of legal theory the hermeneutic viewpoint is prevalent.

This claim is best substantiated by the hermeneutic turn in legal theory in its more abstract manifestation. Paradoxically, it is the legal positivist H.L.A. Hart who has contributed considerably to this approach through his critique on legal positivism of the late $19^{\text {th }}$ and early $20^{\text {th }}$ century. In the wake of the natural sciences, legal positivism advocated that legal theory should be confined to a descriptive-explanatory theory of law, as distinguished from theories or opinions about what law ought to be. ${ }^{10}$ Its propositions should be based upon observations that could be stated in empirical terms, in order to be susceptible to confirmation and repudiation by other observers of the practice.

But the reduction of legal phenomena, such as rules and obligations, to observable facts only comes at a price. The reduction results in a description of the legal institution that accounts for the power the law exerts over its justiciables only in terms of 'prediction' and 'behaviour'. Alf Ross, for example, one of the leading Scandinavian Legal Realists, reduces the notion of legal validity to two empirically verifiable facts: to say that a rule is a valid rule is in fact to say (1) that courts will under specific conditions apply this rule or regard it as especially important in reaching their decision, and (2) that the courts do so, because they have a certain feeling that accompanies their use of this rule, i.e. an emotional experience of 'being bound' by the rules. ${ }^{11}$

In a review of Ross's book On Law and Justice, ${ }^{12}$ Hart remarks that, although Ross's distinction between an internal as well as an external aspect of social rules is an important one, Ross draws the line between these aspects in the wrong places. ${ }^{13}$ If a social group really has rules and not merely a set of convergent habits, these rules functions as standards for conduct. When, for instance, the judge uses the expression that a rule is 'legally valid', she is not predicting her own behaviour, nor describing her feelings of compulsion. It is used in a normative way, that is, as an internal statement in the sense that it manifests her acceptance of the standard..$^{14}$ 'Acceptance' is, among other things, a state of mind, a disposition, which cannot be empirically observed. The same holds for the claims and justifications based upon the acceptance of a standard. These are expressed by a distinctive normative vocabulary such as 'ought', 'should',

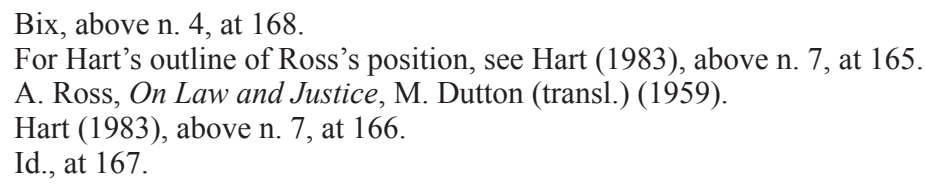


'right' and 'wrong'. To have a full grasp of what it means to obey or violate a rule, the empirical vocabulary of 'regularities' of behaviour following a course of action does not account for the cause of those reactions. For the cause of these regularities is not a law-like response as in physics (the rule does not state that some response will follow), but a normative response that encloses the justification of that response (the rule justifies the response). The proper study of law needs, therefore, a vocabulary of the inner world of the mind, or, to use Hart's terms, legal theory must look upon the rules of a legal system from an internal point of view as accepted standards of behaviour. ${ }^{15}$ And as the recognition of regular behaviour in terms of accepted standards requires an appeal to the scholar's own normative experiences, the viewpoint of the legal scholar might properly be characterised as a hermeneutical viewpoint.

Although Hart's distinction has been subjected to numerous comments, amendments and critiques ever since the publication of The Concept of Law, his claim that legal theory has to understand legal practice in a way that takes into account the way the practice is perceived by, at least, the legal actors, is generally accepted. ${ }^{16}$ In this respect, one might claim that the hermeneutic viewpoint is the paradigm for legal theory.

The same holds for legal theory on a more concrete level: legal doctrine. To determine the meaning of a statute or ruling requires that one considers its point or value. This can only be fully addressed from the perspective of the members of society, that is, as someone who considers this particular statute or ruling as a claim that has a normative appeal to her. The perspective of the legal scholar is the perspective of the participants in the legal practice. The majority conceives of the rules of the legal system not primarily as regularities of behaviour or orders backed by threats. They rather regard the law as a normative order that offers justificatory reasons to act as it prescribes and to impose sanctions in case of violation. ${ }^{17}$ In this respect, the perspective of the legal scholar is similar to that of the judge. Both judge and legal scholar consider the law as the authoritative source of rights and duties, as a normative order that binds its members. Scholar and judge primarily differ in the degree they feel free to disregard or criticise particular elements of the legal order. The judge, after all, is constrained by the peculiarities of her office - she is part of a body that is subordinate to the legislator or, in common law systems, bound to prior decision (stare decisis), and an official whose decisions directly affect citizens and businesses - whereas the scholar is free to criticise a regulation or ruling that is deemed to be incompatible with the basic principles of the system. But in order to make sense as a statement about current law, the critique has to be based on the acceptance of the law as authoritative and has to be framed in terms of the system.

This is the position of the American legal philosopher, Ronald Dworkin, one of the most influential theorists of the late $20^{\text {th }}$ century on the topic of legal adjudication. According to Dworkin, each interpretation of the law entails a critical examination of its normative point or value in light of the values of the system. The proper stance of the judge is not neutrality and objectivity (the alleged error of legal positivism), but integrity: the disposition of someone whose personal opinions about justice, albeit bridled by the system, are a necessary condition for a true understanding of the law. ${ }^{18}$ Interpreting the law, therefore, demands a normative standpoint, a standpoint that entails an internal - participant's - point of view. ${ }^{19}$

Although Dworkin has eloquently elaborated some of the philosophical and esoteric aspects of the methodology of legal adjudication, he is certainly not the first to reject objectivism or formalism as a virtue of legal adjudication. The names of a former generation of influential legal theorists, such as François Gény (France), Benjamin Cardozo and Lon Fuller (United States), Helmut Coing and Joseph Esser (Germany) and, for the Netherlands, Paul Scholten, are associated with a conception of legal adjudication that emphasises the elements of evaluation and judgment. ${ }^{20}$ As evaluation

H.L.A. Hart, The Concept of Law (1961, rev. ed. (with postscript) 1994), at 87-91.

See, among others, Lenoble, above n. 4; Bix, above n. 4.

Hart (1994), above n. 15, at 90.

R. Dworkin, Law's Empire (1986) esp. chapters 6 and 7.

Id., at 14.

F. Gény, Méthode d'interprétation et sources en droit privé positif: essai critique $\left(1919,2^{\text {nd }}\right.$ ed.); 
and judgment are normative in character, legal adjudication and legal doctrine, which is only the scholarly variety of legal adjudication, presuppose an internal point of view. In this respect, one might with some exaggeration say that philosophical hermeneutics merely exposes the epistemological assumptions that buttress the opinions about the nature of legal adjudication that have been generally accepted by lawyers and legal theorists.

\section{5}

Although hermeneutics had originally been developed so as to cut off the hegemony of the alleged 'scientific' methodology of the natural sciences and to develop an alternative for the humanities, philosophical hermeneutics ultimately challenged the ontological assumptions of the scientific project as such. The stumbling block for philosophical hermeneutics is the distinction between subject and object. This distinction is prerequisite to the idea that the purpose of science is to give a true explanation of the world, that is, to develop theories about the world as it is. However, the problem is how to get access to the world 'as it is', since the dominant theory on perception both in the sciences and the humanities holds that all perception is theory-laden, subjective or established by cultural preconceptions. This epistemological claim, strongly argued for by philosophical hermeneutics, has nevertheless experienced strong inhibitions for its alleged consequence of relativism - an extremely inconvenient position for scientists and lawyers, as I will discuss in section 6 . The threat of relativism might explain the persistence of the issue of the subject-object partition in legal theory, and the different ways it has been interpreted. The debate between Ronald Dworkin and Stanley Fish on freedom and constraint in legal adjudication offers an illuminating example of the different explanations of the constitutive role of the subject in literary and legal interpretation that spark off from the hermeneutic paradigm.

Dworkin's theory on legal adjudication is best explained by his resistance against judicial discretion as it appears in Hart's positivist theory of law. According to Hart, a legal system consists of rules, the application of which requires a choice in what is called a 'hard case', as opposed to the plain case, where there is general agreement in judgments as to the applicability of the classifying terms of the rule concerned. In hard cases, says Hart, the judge has discretion, so that if he applies the rule, the conclusion, even though it may not be arbitrary or irrational, is in effect a choice. ${ }^{21}$

This rule-producing function that the courts allegedly exhibit at the margin of rules, is vehemently contested by Dworkin. He challenges Hart's analysis of the law as a system of (primary and secondary) rules only. Dworkin asserts that the law also consists of principles that are not necessarily stated or promulgated, but are implicit in the law. The principles are the normative background of the legal system, offering a justification for the rights and duties that are inferred from the existing body of rules. In this respect, principles direct the interpretation, for the meaning attributed to a rule has to be in accordance with the underlying principles. As a result, the decision in hard cases is not the judge's free choice, but something that is, in an elusive way, already implicit in the body of law. The right decision, then, is the answer on that legal issue that has to be discovered. The upshot of Dworkin's analysis is his famous, but much contested 'one right answer thesis', denying that the judge has strong discretion in hard cases. ${ }^{22}$

This thesis has been interpreted as a regulative ideal of all interpretation, an ontological claim, a methodological assumption, an anti-sceptical stance, a normative

B.N. Cardozo, The Nature of the Judicial Process (1921); Lon L. Fuller, The Morality of Law (1964); H. Coing, Die juristischen Auslegungsmethoden und die Lehre der allgemeinen Hermeneutik (1959); J. Esser, Vorverständnis und Methodenwahl in der Rechtsfindung. Rationalitätsgrundlagen richterlicher Entscheidungspraxis (1970); P. Scholten, Mr. C. Asser's handleiding tot de beoefening van het Nederlands burgerlijk recht. Algemeen Deel (1931).

21 Hart (1994), , above n. 15, at 127.

22 R. Dworkin, Taking Rights Seriously (1977) ch. 13. 
prerequisite of legal interpretation and many other things. ${ }^{23}$ It is outside the scope of this article to analyse these responses in more detail. Instead, I would like to focus on one plausible reading of Dworkin's account of legal interpretation, according to which Dworkin defends a subject-object partition so as to avoid the pending danger of relativism that seems to stick to the hermeneutical stance.

Dworkin's article, 'Law as Literature', ${ }^{24}$ and the response by Fish, 'Working on the Chain Gang: Interpretation in Law and Literature', ${ }^{25}$ are the fruits of their debate on this topic during several conferences. ${ }^{26}$ Dworkin's thesis is that, although legal interpretation is an ultimately normative process, judges are nevertheless constrained by the hard data of the law, such as statutory law and precedents. These hard data are given, for it is a judge's duty, as Dworkin states, 'to interpret the legal history he finds, not to invent a better history'. ${ }^{27}$ What he 'finds' are the hard data of the law; and the interpretation of it has to determine "what the earlier decisions come to, what the point or theme of the practice so far, really is' ${ }^{28}$ This is the dimension of 'fit' that all genuine interpretation has to display. The normative aspect of legal interpretation consists in the dimension of justification of the legal practice as it is found: it has to show the point or value of that body of law in political terms by demonstrating the best principle or policy it can be taken to serve. ${ }^{29}$ Although the dimension of justification brings into the processes of interpretation a subjective element, Dworkin assures us that, thanks to the constraints of the hard data of the law - the text - legal adjudication will not deteriorate into inventing better law according to the personal politics of the judge.

Dworkin's account of legal interpretation obviously fits in with the hermeneutic viewpoint as far as it concerns the researcher's or judge's perspective: for genuine interpretation demands that one looks upon the law from an internal perspective, from the perspective of the members of the community, who consider the regulations as standards that serve as justification for their behaviour and that of others. ${ }^{30}$ But his account of the dimension of 'fit' seems to smuggle in the subject-object partition that philosophical hermeneutics had expelled so boldly from the account of understanding.

The gist of Fish's critique is that Dworkin locates the constraints on interpretation in the wrong place, due to a misunderstanding of the nature of interpretation. ${ }^{31}$ For the real constraints on interpretation are not located in the object; they are social. Texts, says Fish, do not manifest themselves as brute facts, but appear to us only in interpreted form:

[O]ne doesn't just find a history; rather one views a body of materials with the assumption that it is organized by judicial concerns. It is that assumption which gives a shape to the materials, a shape that can then be described as having been 'found'. ${ }^{32}$

Whether or not an interpretation sufficiently fits the text, is not determined by the text as such, but by the text as it is read. The dimension of 'fit', therefore, is not an objective standard, determined by the raw data that everybody 'finds'; rather, it refers to the conventions and strategies of a particular 'interpretive community' of how a text has to be read. These conventions and strategies organise the body of materials in such a way that a particular reading appears to have a better fit than others. Different interpretive communities will, therefore, assess differently the degree of fit between an interpretation and the text, and the dispute cannot be settled with reference to the text, but has to be

\footnotetext{
23 For twenty-four varieties of the 'one right answer thesis', see K. Rozemond, 'Vierentwintig varianten van de one right answer thesis' in E.T. Feteris et al. (eds.), Met recht en reden (2000) 65-71.

24 R. Dworkin, 'Law as Literature' (1982) 60 Texas L. Review 527-550.

25 S. Fish, 'Working on the Chain Gang: Interpretation in Law and Literature' (1982) 60 Texas L. Review 551-567.

26 See the introduction to this special issue on legal interpretation, (1982) 60 Texas L. Review i-iv.

27 Dworkin (1982), above n. 24, at 544 (emphasis added).

28 Id., at 543 (emphasis added).

29 Id., at 544

30 A more inclusive group than in Hart's theory, as for Dworkin legal interpretation is about the politicalmoral justification of the legal system from the perspective of the citizens who are subjected to it: Dworkin (1977), above n. 22, esp. ch. 4.

31 Fish, above n. 25, at 562 .

32 Id., at 557.
} 
fought out on the field of the alleged goals, purposes, concerns and procedures of the institution - on what Dworkin has coined the dimension of justification. The upshot of Fish's critique is that the dimensions of 'fit' and 'justification' are not distinct, as Dworkin holds, with the former constraining the latter, but are inextricably interwoven. And this proposition entails, in fact, another one that buttresses the entire enterprise of philosophical hermeneutics: the thesis that, in the act of understanding, a strict partition of subject and object is untenable.

6

On the mundane level of judicial practice, the positions of Fish and Dworkin do not differ very much. Both reject the two extremes that divide the field of interpretation 'between those who believe that interpretation is grounded in objectivity and those who believe that interpreters are, for all intents and purposes, free'. ${ }^{33}$ They both admit that interpreters' normative opinions, whether or not these may be labelled as ideology, are a constitutive element of interpretation, although the interpreter or judge is not free to invoke any set of opinions. In this respect, one might expect that their account carries the general assent of legal practitioners and judges. They feel forced to employ a standard set of methods or 'legal grammar' that constrains the interpretation and application of the law, although it does not wholly determine the decision. ${ }^{34}$ They share, in short, the same paradigm for legal adjudication. ${ }^{35}$

The difference between Dworkin and Fish is primarily theoretical. It is concerned with the explanation of the nature of the constraints. Dworkin's position is not fully consistent, for he admits that what counts as 'the text' rests upon a subtheory about the identity of a work, and that subtheory, he continues, will also be controversial. ${ }^{36}$ But if the identity of the text actually depends on opinions, conventions or theories, our interpretation is, strictly speaking, not constrained by the text itself, but by our opinions or assumptions on how to identify the text, as Fish rightly points out.

We can only guess what prevented Dworkin from drawing the inevitable conclusion that even the text cannot serve as an external constraint on interpretation. In my opinion, it is connected with the idea that a constraint we ourselves have called into being, is not a constraint at all - with the idea that if interpretation is not constrained by something 'given', but by contingent practices that we ourselves constitute, all interpretation is, ultimately, arbitrary. Under the surface of the analysis of 'understanding' by philosophical hermeneutics, the spectre of relativism looms. For many, relativism is itself an objectionable position, and it has been contested for a range of reasons. ${ }^{37}$ Lawyers have at least one specific reason to object to relativism. In our legal institution, judges are subordinate to the law: they have to administer justice according to the law. The presupposition is that the law has a meaning, and that it is possible, at least in theory, to determine this meaning. However, if we hold epistemological relativism to be true, it would not be the law that determines the decision, but the caste of judges or interpreters that asserts the meaning of the law. Relativism would therefore subvert the law's authority. The threat of relativism might explain why Dworkin holds on to the idea that the text, even though it rests upon a contested subtheory about identity, nevertheless functions as the frozen limit of all interpretation, as the objective criterion to distinguish between genuine interpretation and mere 'invention'. To put it in a phrase Dworkin

Id., at 551.

34 The term 'legal grammar' is used by Koskenniemi, above n. 2, at 568, signifying a limited number of rules that constitute the system of the production of good legal arguments.

35 Cf. one of the descriptions of a paradigm by Kuhn, as 'a standard set of methods or of phenomena that every ... researcher felt forced to employ and explain'. Kuhn, above n. 6, at 12.

36 Id., at 531.

37 For some of those reasons, see, among many, Larry Laudan, Beyond Positivism and Relativism (1996); Paul Boghossian, Fear of Knowledge: Against Relativism and Constructivism (2006). 
would never use for the obvious fallacy it contains, although it can be extracted from his work: the text is an external constraint, because interpretation must be externally constrained. ${ }^{38}$

At best, philosophy is a rigorous discipline, a stringent mode of reasoning, that reveals that we sometimes jump to conclusions that are insufficiently warranted or incompatible with more basic assumptions. It might reveal that a favourite idea rests upon poor grounds, so that we have to reconsider the validity of our beliefs or the grounds on which we hold these ideas to be true. In this respect, philosophy might confront us with inconvenient truths. But an inconvenient truth is still a truth. If our basic assumptions about interpretation - especially the repudiation of a strict partition between object and subject - lead us to the conclusion that interpretation depends upon contingent factors, the inconvenience of this conclusion does not transmute the reasoning into a sophism. In this respect, Fish's critique that Dworkin's account of interpretation is inconsistent or half-hearted is warranted. If all interpretation is directed towards the determination of the meaning, sense or point of a text for us - a standpoint that Dworkin advocates - we then are, in a complex way, always part of the text - a standpoint that Dworkin rejects. Dworkin's fear that the lack of an external constraint results in an unsettling interpretive freedom, says Fish, is misplaced, and displays his poor understanding of the nature of interpretation. Interpretation is not an enterprise in need of constraints, but a structure of constraints. It is the institution, not the thing interpreted, which constrains.

Though theoretically impeccable, Fish's response is unsatisfactory in one respect. A novel is certainly enriched by multiple readings that offer different perspectives on that work. Even when these readings are incompatible or hostile to one another, they often coexist, in that different 'interpretive communities' simultaneously read, reflect and respond on that work of art. Especially in the humanities, different schools or paradigms vie with one another, enriching the soil of our understanding of cultural and social life. But law is a different phenomenon. It is, on the one hand, a phenomenon that can be studied from different disciplines and perspectives. Both our understanding and the development of the institution will, in the long run, benefit from the various voices that comment on it. On the other hand, law is also a social institution that regulates social life. As it interferes deeply in the life of the members of the community, the key values of the legal system are, among other things, legal certainty, uniformity, and predictability. These values are the prerequisites for the functioning of a stable legal system. They are a kind of internal morality of the law that allows the members of the community to adjust their acts and mutual expectations to the directives of the law. ${ }^{39}$ Even if we agree that all interpretation is always constrained by some standards that hold for some interpretive community, as Fish states, the principal question for legal practitioners is which standards, out of many, ought to govern the interpretation and application of the law of their community. The legal community needs a standard set of methods that its competent members feel forced to employ, that is, a paradigm for the legal profession. Dworkin might have located these constraints in the wrong place, but he rightly considered the legal enterprise as an enterprise in need of constraints, which cannot be substituted for different ones due to a judge's ideological or scientific preferences. And if we credit the hermeneutic viewpoint, the judge must not only feel forced to use these standards, but she has to accept them as the appropriate set of standards as well.

\footnotetext{
38 See Dworkin (1982), above n. 24, at 543 (emphasis in original): 'He must interpret what has gone before because he has a responsibility to advance the enterprise in hand rather than strike out in some new direction of his own.'

39 See L.L. Fuller, The Internal Morality of Law (1963, rev. ed. 1969).
} 
Philosophy exhibits a paradox. It tries to understand man, society and the world rationally. The fruit of this endeavour is an innumerable amount of philosophical accounts, which are each subject to critical philosophical examination. Judged by the rigorous standards of rationality, all philosophical explanation turns out to be inadequate in some respects, for neither its premises nor its criterion of truth can be fully accounted for, that is, rationally justified. The sceptics, evaluating the validity of the rational accounts and explanations of other philosophers and theorists, reproach them with holding a naive faith in reason or, what in fact boils down to the same thing, for not being rational enough. Seen from this perspective, the debate between Dworkin and Fish might be comprehended as the continuation of the fight between some variety of rationalism and scepticism from within the hermeneutic paradigm. Dworkin's 'right answer' thesis is a defence of legal interpretation as a methodologically constrained activity to such a degree that the decision, even in hard cases, can be rationally justified. The sceptic Fish rebuts this conclusion, for the decisions of judges are rational only to the degree that they share a set of interpretive standards - standards that make up the dimensions of fit and justification. To the extent that all theory and all judgment are inextricably intertwined with the mundane banalities of everyday life, our acceptance of a philosophical posture or judicial decision is not rational at all, but, on a fundamental level, illogical or groundless.

Despite their controversy, rationalism and scepticism share a language or grammar, which positions them not as two different worldviews but as two extremes in the same enterprise: the search for rational truth. In my opinion, the sceptics are the more strict rationalists, who draw out the utmost consequence of their analysis: that the mission for truth is doomed to fail, because the criterion of rationality is itself not neutral and objective. Relativism, so conceived, is not the opposite of rationalism, but its extreme consequence. However, the rightness of the relativistic position holds under the assumption that, in order to be true, a proposition must be rationally attested, an assumption that itself cannot be rationally warranted.

The controversy between rationalism and scepticism seems unsolvable. Rationalism incessantly runs up against the limits of reason, whereas scepticism's predicament is that it repudiates rationalism on the basis of a rational critique that presupposes, but cannot prove, its validity. It seems that the only way out is challenging the shared concept of truth as rational truth, that is, the idea that a proposition is true if, and only if, its validity can be warranted on rational grounds. In fact, the hermeneutic viewpoint points towards a different approach, although it is speech act theory that is most promising in this respect.

The import of speech act theory for legal theory is that it meets the need for a common ground that secures the reasonableness of legal interpretation, while simultaneously acknowledging that reason itself cannot fully account for it. However, the merits of speech act theory for law are not only philosophical. It also suggests a legal methodology for the study of law, one that exposes the deep structure or 'grammar' of argumentative schemes in legal debate and controversy.

In order to fully grasp how the challenge of relativism is countered by speech act theory and, albeit half-heartedly, by hermeneutics, I will first discuss how both approaches deal with the issue of truth and arbitrariness in meaning and interpretation. I will particularly address the works of two philosophers, namely Truth and Method by H.-G. Gadamer and Wittgenstein's Philosophical Investigation and On Certainty, which so deeply influenced speech act theory. In section 10 and further, I will discuss the implications of their approach for legal theory.

The decisive shift in philosophical hermeneutics is made by Gadamer, in the wake of Heidegger's phenomenological description of the fore-structure of understanding. 'A person,' says Gadamer, 'who is trying to understand is exposed to distraction from 
fore-meanings that are not borne out by the things themselves. ${ }^{, 40}$ The constant task of hermeneutics is "working out appropriate projections, anticipatory in nature, to be confirmed "by the things" themselves. ${ }^{41}$ But the true object of understanding is not the 'thing itself', but the unity of 'understanding one's own historicity' and the thing that is the object of understanding. ${ }^{42}$ The real task in understanding is to examine explicitly the legitimacy - i.e. the origin and validity - of the fore-meanings dwelling with the interpreter, for 'understanding realizes its full potential only when the foremeanings that it begins with are not arbitrary. ${ }^{43}$ True understanding is the interplay of the movement of tradition and the movement of the interpreter: 'The anticipation of meaning that governs our understanding of a text is not an act of subjectivity, but proceeds from the commonality that binds us to the tradition. ${ }^{44}$

Although the wording is somewhat ethereal, the main theses of philosophical hermeneutics, as we discussed earlier, are present here. First, the text is not given, but is given shape in the act of understanding (the unity between object and one's own historicity). Second, understanding always involves the prejudices of the interpreter - the fore-meanings or fore-structure of understanding. Third, understanding is not arbitrary, for the prejudices have to be secured, as Heidegger says, by working out the fore-structures in terms of the things themselves. ${ }^{45}$ Fourth, 'correct' prejudices are secured by the tradition we belong to (the history the judge 'finds', as Dworkin puts it). Although tradition is not simply a permanent precondition - it is produced by ourselves inasmuch as we participate in the evolution of tradition ${ }^{46}$ - neither it is a mere subjective experience of historical events. As Gadamer succinctly states: ' $[\mathrm{H}]$ istory does not belong to us; we belong to it. ${ }^{47}$

For philosophical hermeneutics, the role of tradition is vital for true understanding. Although we are always situated within traditions, we have to be addressed by tradition. We should not approach a text directly, relying solely on the prejudices already available to us, but rather explicitly examine the legitimacy of the fore-meaning dwelling within us. ${ }^{48}$ The problem for true understanding is not that understanding is grounded in prejudice or fore-structure, but that our prejudices might be arbitrary for being poorly connected with tradition. Tradition, for Gadamer, is the whole of texts, institutions and persons, whose authority is recognised in an act of acknowledgement and knowledge - the knowledge that the other is superior to oneself in judgment and insight and that for that reason his judgment takes precedence. ${ }^{49}$ The recognition of authority doesn't mean that tradition is accepted in blind obedience, but that it is considered, affirmed, embraced and cultivated ${ }^{50}$ It is not something given, not a brute fact, ${ }^{51}$ but something that is, as it were, produced by innumerable acts of the participants in the practice. Tradition, in short, is an institution. And the correctness of an interpretation is connected with the institution as it rises up out of the practices that constitute it.

The term 'institution' refers to another important philosophical tradition of the $20^{\text {th }}$ century: speech act theory. Although the philosophical roots of hermeneutics and speech act theory are worlds apart, they share an important insight. They both discard the idea of the faculty of reason as an independent and autonomous source of knowledge. Both hold that our thoughts and ideas are not the fruits of the individual mind, the meaning of which could only be known by the person who experiences, or produces, them. Rather, they are intimately connected to the way the words and concepts, which are applied to

40 H.-G. Gadamer, Truth and Method, transl. by J. Weinsheimer and D.G. Marshall of Wahrheit und Methode (1975, rev. ed. 1989) at 267.

41 Id., at 267.

42 Id., at 299.

43 Id., at 267.

4 Id., at 293.

45 M. Heidegger, Being and Time, transl. by J. Macquarrie and E. Robinson of Sein und Zeit (1962) at 153.

46 Gadamer, above n. 40, at 293.

47 Id., at 267.

48 Id., at 276.

49 Id., at 279.

50 Id., at 281

51 For the term 'brute fact', see J.R. Searle, The Construction of Social Reality (1995) ch. 1. 
express those mental experiences, are used in the community of which she is part. Ideas and thoughts, therefore, belong as much to the social world as they are individual; they are a mental activity as well as a way of acting.

Speech act theory, firmly rooted in the work of Ludwig Wittgenstein and John. L. Austin, ${ }^{52}$ has developed a sociological view on knowledge. According to this view, every statement about nature and man is embedded in a network of statements, which together form an institution. The institution of a natural language might be illuminating in this respect. To speak a language is to participate in an institution. Each language user is subject to the standards of correct language use, but the standards are dependent on their use by the community of language users. As such, language is a social construction that derives its existence from being performed. In this respect, there is no true essence of English, Dutch or Papiamento, except for the way it is spoken. One might conclude that, as a language is 'just' a social construction, and therefore contingent in its shape, it cannot be normative - for there is no absolutely wrong or correct way to speak that particular language. But this is not the way we deal with language. Children learn a language by following examples, and they are corrected when they commit an error - that is, when they deviate from the rule. The rigorous training in correct speaking and writing explains the perception of one's mother language as a rather fixed and immutable phenomenon to such a degree that purists resist the influx of loan words and expressions, barbarisms that are at variance with what they consider to be the true essence of their language.

What holds for the institution of natural languages, holds for all institutions. The philosophical claim of speech act theory is that all knowledge is based upon institutions. The intellectual superstructure of our knowledge, including those parts that seem purely mental, such as arithmetic, is built upon a way of acting. In Philosophical Investigations and On Certainty, Wittgenstein meticulously analyses what justifies the solution of simple arithmetic problems, or our acceptance of a proposition, the truth of which is beyond reasonable doubt. For these propositions, he states, a rational proof cannot be given, because each reason is itself in need of justification. In the end, we just accept the proposition, not on rational grounds, but because it is the way we $d o$ things. The solution of a complex arithmetic problem, for example, might be justified with reference to a standard set of rules or standards that determines the solution. But the presupposition is that we apply those rules correctly - that we know how to handle them - and this kind of knowledge is firmly based upon practices that have been learned through endless processes of copying, repetition and rectification. ${ }^{53}$ Here, at the foundation of our knowledge, the tight connection between knowledge and action becomes manifest: finally, we can justify the way we count and subtract - following some rule - only by reference to the way we $a c t$, as Wittgenstein states in a much cited paragraph:

'How am I able to obey a rule?' - if this is not a question about causes, then it is about the justification for my following the rule in the way I do.

If I have exhausted the justifications I have reached bedrock, and my spade is turned. Then I am inclined to say: 'This is simply what I do. ${ }^{54}$

The same holds for propositions that we take to be certain. Take the 'truisms' that G.E. Moore mentioned in his 'Proof of an External World', e.g. that he knew that there was one hand in the place indicated by combining a certain gesture with his first utterance of 'here' and that there was another in the different place indicated by combining a certain

52 L. Wittgenstein, Philosophische Untersuchungen/Philosophical Investigations, G.E.M. Anscombe and R. Rhees (eds.), G.E.M. Anscombe (transl.) (1953); J.L. Austin, How to do Things with Words (1962, rev. ed. 1975).

53 See L. Wittgenstein, Über Gewissheit/On Certainty, G.E.M. Anscombe and G.H. von Wright (eds.), D. Paul and G.E.M. Anscombe (transl.) (1969) § 44: 'If you demand a rule from which it follows that there can't have been a miscalculation here, the answer is that we did not learn this through a rule, but by learning to calculate.' Also § 212: 'In certain circumstances, for example, we regard a calculation as sufficiently checked. What gives us a right to do so? Experience? May that not have deceived us? Somewhere we must be finished with justification, and then there remains the proposition that this is how we calculate.'

54 Wittgenstein (1953), above n. 52, at § 217. 
gesture with his second utterance of 'here'. ${ }^{55}$ Wittgenstein objects to Moore's account, for his truisms are not subject to 'knowledge' in the same way as statements that are less obviously certain, like propositions about the precise distance between earth and sun:

The propositions presenting what Moore 'knows' are all of such a kind that it is difficult to imagine why anyone should believe the contrary. E.g. the proposition that Moore has spent his whole life in close proximity to the earth. - Once more I can speak of myself instead of speaking of Moore. What would induce me to believe the opposite? Either a memory, or having been told. - Everything that I have seen or heard gives me the conviction that no man has ever been far from the earth. Nothing in my picture of the world speaks in favour of the opposite. ${ }^{56}$

The same holds for the truism that the earth existed for many years past. This is not something we assume, as if we could also reasonably assume the opposite. We do not know it, in the sense of knowing it to be true, but it stands fast for us; and to regard it as absolutely solid is part of our method of doubt and inquiry: $:^{57}$

$[\mathrm{I}] \mathrm{n}$ the entire system of our language-games it belongs to the foundation. The assumptions, one might say, forms the basis of action, and therefore, of thought. ${ }^{58}$

It is in this sense that Moore's truisms, although we cannot prove them to be true, are not arbitrary. Their role is like that of the rules of a game. They have a peculiar logical role in the system of our empirical propositions, for it is against the inherited background of those truisms or convictions that we distinguish between true and false: ${ }^{59}$

All testing, all confirmation and disconfirmation of a hypothesis takes place already within a system. And this system is not a more or less arbitrary and doubtful point of departure for all our arguments: no, it belongs to the essence of what we call an argument. The system is not so much the point of departure, as the element in which arguments have their life. ${ }^{60}$

Much more could be said about the role of these truisms or self-evident truths in our thinking, but, for the sake of my argument, the most important aspect is that these truisms are not learned through rules: we are taught judgments and their connection with other judgments; and it is this totality of judgments that is made plausible for us. ${ }^{61}$ That is the way a child learns to believe many things. It learns to act according to these beliefs and bit by bit there forms a system of what is believed. 'What stands fast,' says Wittgenstein, 'does so, not because it is intrinsically obvious or convincing; it is rather held fast by what lies around it. ${ }^{62}$ The truth of these truisms is not rational truth, for it is the background of beliefs against which we distinguish between true and false. At the foundation of well-founded belief lies belief that is not founded, but inherited: ${ }^{63}$

If the true is what is grounded, then the ground is not true, nor yet false. ${ }^{64}$

The similarity between the role of tradition in the account of philosophical hermeneutics and the role of truisms in Wittgenstein's account is obvious. They both serve as the foundation of our judgments and knowledge, a foundation that cannot be rationally justified. Nevertheless, they significantly differ in one respect. Gadamer emphasises the aspect of reason in the acknowledgement of the authority of tradition, whereas Wittgenstein considers the truisms to be beyond true and false. Authority, says Gadamer, must be earned. It rests on acknowledgment and hence on an act of reason itself. Authority in this sense has nothing to do with blind obedience to commands, but rather with knowledge. ${ }^{65}$ But one might ask, with Wittgenstein, what kind of knowledge it is

55 G.E. Moore, 'Proof of an External World', Proceedings of the British Academy 25 (1939) 273-300.

56 Wittgenstein (1969), above n. 53, at §93. The example is outdated, for nowadays at least some men and women have left the earth's atmosphere.

57 Id., at $\S 151$.

58 Id., at $\S 411$. See also § 204: 'Giving grounds, however, justifying the evidence, comes to an end; - but the end is not certain propositions' striking us immediately true, i.e. it is not a kind of seeing on our part; it is our acting, which lies at the bottom of the language-game.'

59 Id., at $\S 94$.

60 Id., at $\S 105$.

${ }^{61}$ Id., at $§ 140$.

62 Id., at $\$ 144$

63 Id., at $\$ 253$.

64 Id., at $\S 205$.

65 Gadamer, above n. 40, at 279. 
that induces someone to accept one tradition rather than another - for we already belong to tradition. And part of the reasons for accepting one version or reading of tradition is grounded on judgments - judgments that themselves cannot be deliberately accepted, because they are constitutive of acceptance and rejection.

It seems that even Gadamer shies away from drawing the conclusion, implicit in his account of understanding, that reason is not at the base of knowledge, but groundless beliefs. By emphasising the aspect of reason in handling our prejudices, ${ }^{66}$ he still contrasts irrationality and arbitrariness with reason. Wittgenstein's account seems more accurate to me: it is on the basis of unfounded beliefs that we can judge propositions to be irrational, arbitrary, false or true. What gives them their credit, is the way we act. Not theory, but practices are at the bottom of knowledge.

\section{0}

The crucial step by Wittgenstein in his reflection on truth is that he connects knowledge, and therefore meaning and interpretation, with practices. Our thinking is tributary to the way we act, both as a matter of how we actually learn as well as epistemologically. That made him subject to the reproach of relativism. For if truth is a function of groundless beliefs, does this not, in fact, get rid of the notion of truth as such and exclude a right answer in serious disputes, when worldviews clash? That, indeed, is Wittgenstein's position. If a king, asks Wittgenstein, has been brought up in the belief that the world began with him, could Moore really prove his belief to be the right one, if they were to meet and discuss?

I do not say that Moore could not convert the king to his view, but it would be a conversion of a special kind; the king would be brought to look at the world in a different way. ${ }^{67}$

He would, for example, be induced to go over to this point of view because of its simplicity or symmetry. At the end of reasons, adds Wittgenstein, comes persuasion. ${ }^{68}$ This account excludes right answers and absolute truths in the case of incompatible worldviews. But Wittgenstein would dismiss the term 'relativism' as a characterisation of his position. The predicate 'true' or 'false' of a proposition makes sense only within a system of beliefs - or form of life - that we hold fast. But to call a form of life or worldview 'true' or 'false' is senseless, for we would have to judge the very foundation of our judgments - as if we have to determine the 'true' value of a currency apart from banks, exchange rates, trade and savings balances, institutions that together make up the institution of money. We can, of course, say that different worldviews are equally worthwhile, but such an assertion reveals, at best, something about our own worldview, not about the alleged value of others.

The connection between knowledge and practices removes the arbitrariness of our judgments. Truth is a function of being grounded - and our most firm beliefs are grounded, not upon propositions whose truths are, from a rational point of view, selfevident or manifest, but upon a way of acting from which many truisms may be inferred. The existence of an external world, for example, is implicit in the way we act and judge, and we are seldom explicitly taught 'that an external world really exists'. A child does not learn that books and armchairs exist, but learns to fetch books and to sit in armchairs -it swallows their existence, so to speak, together with what it learns. ${ }^{69}$ And law students learn more thoroughly that rights exist through courses devoted to property, tort and procedural law rather than by a philosophical account on the nature of law. ${ }^{70}$ The same holds for the institution of law itself. Its structure and foundation rise from the interplay

66 By using terms like affirmation, embrace and cultivation, Gadamer points towards the aspects of consideration and deliberation, that is, to reason, id., at 281.

67 Wittgenstein (1969), above n. 53, at $\S 92$.

68 Id., at $\S 612$.

69 Id., at $§ 144$

70 The same idea is expressed by Kuhn, who states that concrete models, that is, paradigms, are prior to the various concepts, laws, theories and points of view that may be abstracted from it: Kuhn, above n. 6, at 11. 
between practices and regulations, or to use an intriguing metaphor by Wittgenstein: the foundation-walls are carried by the whole house. ${ }^{71}$ It is our acting in particular cases, not reason, that secures the correctness of our prejudices or fore-understanding.

Wittgenstein's account takes the sting out of scepticism - its paralysing relativism, which does not lead so much to intellectual modesty, but which undermines the credibility of its own account and of the scientific approach as such. But more important perhaps is that it offers a direction how to study social phenomena, such as law. It does not reject rational accounts or explanations as such. Rather, it reveals that these are fertile only if we take seriously the practices through which law, language and other institutions manifest themselves, and thoroughly investigate how words and concepts are used in different contexts. Such an analysis could reveal the deep structure or 'grammar' of a practice, which manifests itself through its vocabulary. For it is through language, conceived of as speech acts, that a social reality is constructed. ${ }^{72}$

Both speech act theory and hermeneutics emphasise that reason manifests itself through the spectra of culture. In this respect, culture matters in law. What is reasonable or true in law cannot be determined apart from the legal system as an historic (or cultural) phenomenon. One might consider this approach as characteristic of post-war European legal thought, influenced as it is by a distinctive 'continental' (i.e. German) theme in philosophy. Continental philosophy is a generic term, including philosophical movements such as phenomenology, existentialism, structuralism and psychoanalysis. ${ }^{73}$ It refers to a set of traditions of $19^{\text {th }}$ and $20^{\text {th }}$ century philosophy from mainland Europe that emphasise the import of factors such as context, space and time, language, culture or history, on science and philosophical thought. ${ }^{74}$ This is particularly manifest in the work of Gadamer (a German philosopher), who regards 'tradition' as the repository of reason. But this 'continental trait' is also patent in the work of the later Wittgenstein (an Austrian philosopher, albeit strongly associated with British analytical philosophy), who treats rationality as an immanent phenomenon, operative on the level of languagegames and forms of life. Their influence on European legal thought has been profound. The hermeneutic approach for law has been developed by scholars such as Karl Larenz, Josef Esser and Karl Engisch, ${ }^{75}$ whereas the development of an analytic hermeneutics, merging the philosophy of the later Wittgenstein and hermeneutics, has been undertaken by, among others, Aulis Aarnio and Ota Weinberger. ${ }^{76}$ It is through these authors that the hermeneutic approach has been generally accepted in legal theory.

The import of culture for the study of law leads me to a development in the social sciences of the past twenty years that appears to be very promising for legal theory: the growing interest in metaphor. ${ }^{77}$ An increasing amount of studies reveal the centrality of metaphor in human thought. ${ }^{78}$ These theories are underpinned by a conception of language as developed by speech act theory, and it is this connection that renders the study of legal metaphor a most promising field of legal research.

\footnotetext{
71 Wittgenstein (1969), above n. 53, at $§ 248$.

2 Searle, above n. 51

73 See B. Leiter, The Oxford Handbook of Continental Philosophy, B. Leiter and M. Rosen (eds.) (2007) at 2 .

74 S. Critchley, Continental Philosophy: A Very Short Introduction (2001) at 57.

75 K. Larenz, Methodenlehre der Rechtswissenschaft (1969, rev. ed. 1983); J. Esser, Vorverständnis und Methodenwahl in der Rechtsfindung. Rationalitätsgrundlagen richterlicher Entscheidungspraxis (1970); K. Engisch, Einführung in das juristische Denken (1964, rev. ed. 1983).

76 A. Aarnio, Linguistic Philosophy and Legal Theory (1987); O. Weinberger, Law, Institution, and Legal Politics: Fundamental Problems of Legal Theory and Social Philosophy (1991).

77 I will leave out a second fertile approach, the institutional theory of law, although I have pointed towards this approach in the previous sections of this article.

78 M. Black, 'Metaphor', Proceedings of the Aristotelian Society 55 (1954) 273-294, reprinted in M. Black, Models and Metaphors. Studies in Language and Philosophy (1962) 25-48. For publications on metaphor, see, among others, A. Ortony (ed.), Metaphor and Thought (1979); Raymond W. Gibbs, The Cambridge Handbook of Metaphor and Thought (2008). Both publications include contributions from different disciplines such as psychology, anthropology, linguistics, cognitive sciences, philosophy and literature.
} 
Metaphor structures understanding. That is, in short, the essence of a developing body of work on human cognition. In a pioneering work, G. Lakoff and M. Johnson examine how our thinking is permeated by metaphors, and how they structure the way we understand reality ${ }^{79}$ They start their book with the concept 'argument', and (one of) the metaphor(s) that direct(s) it: the metaphor 'argument is war'. This metaphor is reflected in everyday language by a host of expressions: claims are indefensible, every weak point in the argument is attacked, someone's argument is demolished, arguments are shot down, etc. ${ }^{80}$ This, however, is not just a matter of language, of mere words, but a way of how we conceptualise argument:

[W]e don't just talk about arguments in terms of war. We can actually win or lose arguments. We see the person we are arguing with as an opponent. We attack his position and defend our own .... Many things we do in arguing are partially structured by the concept of war. ${ }^{81}$

We talk about arguments that way, because we conceive of them that way - and we act according to the way we conceive of things. ${ }^{82}$ Lakoff and Johnson give many examples of metaphors that perform a vital role in our conceptual framework. Some of them are very basic, like the container schema (to see fear in someone's eyes, to have a full life, to get into trouble), spatial metaphors (for example, the 'up-down' metaphors in e.g. 'head of state', 'a higher status'), and the 'source-path-goal' schema (of which the 'life is a journey' metaphor is part).

Two aspects of metaphor are especially relevant here. First, a metaphor is a conceptual schema or model that organises the body of statements that could intelligibly be stated about a topic. If 'love is a collaborative work of art' (a metaphor, for it is neither work nor art according to the alleged literal meaning of the words), then the elements of 'work' and 'art' give rise, among other things, to the following entailments: love requires cooperation, dedication, compromise and discipline; and it is an aesthetic experience, valued for its own sake, creates a reality, is unique, etc. ${ }^{83}$ Each statement is intelligible in light of the metaphor, and together they form a coherent body of propositions. ${ }^{84} \mathrm{~A}$ different schema (e.g. 'love is madness' or 'love is war') would have brought about a different complex of related propositions. ${ }^{85}$ Second, although different metaphors are used to describe similar human experiences (e.g. 'love is war' and 'love is madness', among many others), metaphors are not arbitrary. Like the truisms that Wittgenstein discusses, most metaphors are grounded in systematic correlations with our physical and cultural experiences and the way we deal with them. ${ }^{86}$ The basic experiences provide the organising principles for the construction of conceptual models, like the container schema and the source-path-goal schema. ${ }^{87}$ These are the way reality is experienced and perceived, and they are neither true nor false, because they are part of the conceptual structure that frames judgment.

In this respect - and of special interest for legal theorists - legal theory itself is rife with metaphors. In an article, called "“Penumbra": The Roots of a Legal Metaphor', B. Henly enumerates a multitude of metaphors, sparked off from the spatial schema, that are used to describe the building blocks of law: ${ }^{88}$

G. Lakoff and M. Johnson, Metaphors We Live By (1980).

80 Id., at 4.

Id., at 4.

Id., at 5 .

Id., at 139 et seq.

4 Id., esp. ch. 16.

5 Respectively, the statements 'to be crazy about someone; to be wild about someone' and the statements 'to be known for his conquests; she fought for him, but the other won out': Lakoff and Johnson, above $\mathrm{n}$. 79 , at $87-97$.

86 Id., ch. 13 .

87 For references to empirical work on this topic in experimental psychology, linguistics and anthropology, see Steven L. Winter, 'The Metaphor of Standing and the Problem of Self-Governance' (1988) 40 Stan. L. Review 1371 at 1384 .

88 B. Henly, “"Penumbra”: The Roots of a Legal Metaphor' (1987) 15 Hastings Const. L.Q. 81. 
[L]egal ideas often seem to have weight as well as volume, as when interests are 'balanced'. Spatial metaphors make it possible to visualize change. Doctrines can be extended, narrowed, expanded, and circumscribed. Branches are separated, but not hermetically sealed of. Legal rules develop frontiers, cores, and cutting edges. Without splitting hairs, fine lines get drawn. ${ }^{89}$

These metaphors do not only describe abstract concepts in a way that facilitates comprehension, they also affect the way we act as lawyers. The spatial metaphors add to the view that the law is something that exists 'out there', in the world of objects. But if the law is reified, if it is comprehended as a physical object, fixed by spatial coordinates, then it could bring about the view that law is an object that can be studied in a way that resembles the methods of scientists or, more appropriate here, those of the land surveyor, by 'setting a statute next to the Constitution to see how it measures up'. The use of spatial metaphors to describe law, in short, might explain that lawyers are still attracted to the dubious idea that legal adjudication could be performed neutrally, as detached as a scientist who measures the distance between the Milky Way and the Andromeda Galaxy.

This example reveals that metaphors have normative effects, even if they were initially used to describe a phenomenon or to grasp the similarities between different phenomena. ${ }^{91}$ A prevailing metaphor might explain the deep structure or grammar of the arguments that are put forward on a certain topic; and it might also explain why a strand of arguments sometimes has been discarded.

An example of the latter is provided by the evolution of metaphorical inferences as applied to the Internet within legal commentary and judicial opinion. ${ }^{92}$ As Blavin and Glenn Cohen point out, much of the early thinking about the Internet is shaped by the 'information superhighway' metaphor. This metaphor connotes a transfer of information. The information superhighway is an account of space. The metaphor highlights the resemblances with real highways. Just as real highways are used to transport persons and objects, the Internet can also be conceived of as a means of transportation, for example for messages, like emails. Real highways are regulated by the government, so the metaphor furthers the presumption of (federal) government regulation of the Internet. ${ }^{93}$ This metaphor was eclipsed by another, the 'cyberspace metaphor'. The cyberspace metaphor highlights the fluid character of the Internet. Conceived of this way, the Internet is not a 'real' place, but rather a virtual space, nothing but the flow of digital data through the network of interconnected computers. ${ }^{94}$ Related to this idea is the concept of the Internet as a 'frontier', 'as the $19^{\text {th }}$ century American West in its natural preference for social devices that emerge from its conditions, rather than those that are imposed from the outside. ${ }^{95}$ The metaphor of cyberspace as a novel place, existing outside any territory, was adopted by the Supreme Court, including the normative inference that the Internet was, therefore, potentially immune to real space regulation. ${ }^{96}$ Currently, the 'internet as real space' metaphor has become prevalent, on the footing that the Internet can be moulded to coincide with real territorial boundaries and legal jurisdictions through filtering and geographical pinpointing technologies. ${ }^{97}$ This metaphor will also affect and organise the normative choices that can be made, although it does not mean that the metaphor determines them.

As the law is framed in metaphors, legal metaphor can be found in all legal fields, from corporate law (the doctrine of corporations as legal persons), to procedural law (the doctrine of 'standing') and criminal law (the metaphor of 'terrorism as war'). ${ }^{98}$

Id., at 82.

90 Id..

91 For the heuristic function of analogy and metaphor, see M. Hesse, 'Aristotle's Logic of Analogy (1965) 15(61) Philosophical Quarterly 328-340.

92 J.H. Blavin and I. Glenn Cohen, 'Gore, Gibson, and Goldsmith: The Evolution of Internet Metaphors in Law and Commentary' (2002) 16 Harv. J.L. \& Tech. 265.

93 Id., at 273.

94 Id., at 276.

95 Id., at 267.

96521 U.S. 844 (1997).

97 Blavin and Cohen (2002), above n. 92, at 282.

98 Respectively, Sanford A. Schane, 'The Corporation as Legal Person: The Language of a Legal Fiction' (1987) 61 Tul. L. Rev. 563; Steven L. Winter, 'The Metaphor of Standing and the Problem of Self- 
Metaphors guide the use of fundamental legal concepts, such as sovereignty, will and conscience. ${ }^{99}$ These studies reveal that the use of arguments in law is less arbitrary than pragmatists and critical scholars assume, ${ }^{100}$ if we at least connect the argumentation to the metaphors that constitute the particular discourse. The metaphors themselves are grounded in experiences or ways of perceiving and are, therefore, not susceptible to scientific testing methods to validate their truth-value. But that does not render the argumentation into arbitrary conceptual schemes. They mediate, as Mary Hesse states, a kind of social knowledge and provide evaluations reflecting social interests and judgments of significance. ${ }^{01}$

It seems that Heidegger's fore-understanding, Gadamer's prejudices that are secured by tradition and Wittgenstein's 'forms of life' have taken a more concrete and, so to speak, palpable form through these conceptual models or schemes that bring about the spatial, temporal and substantial metaphors in which the law is framed. In this respect, culture matters in the study of law. Although the very foundation of the conceptual framework displays striking resemblances in different cultures - e.g. the metaphors that stem from the up-down schema - most metaphors are culturally specific, such as the metaphors of battle, sports and sex that are prevalent in American legal discourse on the adversary system. ${ }^{102}$ The study of legal metaphor, therefore, exposes how man, society and reality are comprehended. They offer, as it were, the 'cultural grammar' of a society and deepen our understanding of the argumentative schemes that are operative in legal adjudication.

\footnotetext{
Governance' (1988) 40 Stan. L. Rev. 1371; Louis Henkin, 'War and Terrorism: Law or Metaphor' (2005) 45 Santa Clara L. Rev. 817; and B. van Eekelen et al. (eds.), Shock and Awe. War on Words (2004). In fact, the literature on analogy and precedent could also be added, as the reasoning processes resemble those in the use of metaphor. See, among others, Scott Brewer, 'Exemplary Reasoning: Semantics, Pragmatics, and the Rational Force of Legal Argument by Analogy' (1996) 109 Harv. L. Rev. 923; Dan Hunter, 'Reason is Too Large: Analogy and Precedent in Law' (2001) 50 Emory L.J. 1197; and Cass R. Sunstein, 'On Analogical Reasoning' (1993) 106 Harv. L. Rev. 741.

99 For the concepts of sovereignty and will, see C.E. Smith, 'Soevereiniteit: solipsisme of institutie?' (Sovereignty: solipsism or institution?) in G. Molier and T. Slootweg (eds.), Soevereiniteit en recht. Rechtsfilosofische beschouwingen (2009) 33-52; for the concept of conscience, see C.E. Smith, 'Fenomenologie van de gewetensbeslissing: twee varianten' (Phenomenology of the conscientious decision: two varieties) in A. Ellian et al. (eds.), Recht, beslissing en geweten (2010) 181-200.

100 For a pragmatic view on legal adjudication, see Richard A. Posner, The Problems of Jurisprudence (1993); a more radical scepticism is defended by, among others, Duncan Kennedy, 'Form and Substance in Private Law Adjudication' (1976) 89 Harv. L. Rev. 1685.

101 M. Hesse, 'The Cognitive Claims of Metaphor' (1988) II(1) The Journal of Speculative Philosophy 1 at 8, first published in J.P. van Noppen (ed.), Metaphor and Religion (1984) 27-45.

102 See E.G. Thornburg, 'Metaphors Matter: How Images of Battle, Sports, and Sex Shape the Adversary System' (1995) 10 Wis. Women's L.J. 225, arguing that the metaphorical fixation on the combative, noncooperative aspect of dispute resolution and the suppression of any duty to other litigants, the court system or the community contributes to a professional role that is severely out of balance.
} 